\title{
ELISA based on a recombinant Paragonimus heterotremus protein for serodiagnosis of human paragonimiasis in Thailand
}

Kanokkarn Pothong ${ }^{1}$, Chalit Komalamisra², Thareerat Kalambaheti ${ }^{3}$, Dorn Watthanakulpanich ${ }^{1}$, Timothy P. Yoshino ${ }^{4}$ and Paron Dekumyoy ${ }^{1 *}$

\begin{abstract}
Background: Paragonimus heterotremus is the main causative agent of paragonimiasis in Thailand. In Western blot diagnostic assays for paragonimiasis, the $35 \mathrm{kDa}$ band present in crude $P$. heterotremus somatic extracts represents one of the known diagnostic bands. This study aimed to use a $P$. heterotremus cDNA library to create a recombinant version of this antigen for use in immunodiagnosis of paragonimiasis.

Methods: To accomplish this aim a cDNA expression library was constructed from adult worm mRNA and immunoscreened using antibodies from mice that had been immunized with the $35 \mathrm{kDa}$ antigen. Screening resulted in the identification of an immunoreactive protein encoded by clone CE3, which contained an inserted sequence composed of 1292 base pairs. This clone was selected for use in the construction of a recombinant $P$. heterotremus protein because of its similarity to proactivator polypeptide. For recombinant protein expression, the CE3 gene sequence was inserted into the plasmid vector pRset and the resulting product had the expected molecular weight of $35 \mathrm{kDa}$. An IgG-ELISA based on the CE3 recombinant protein was evaluated by using sera from healthy individuals, from patients with paragonimiasis and other parasitic infections. This ELISA was performed by using human sera diluted at 1:2000, an optimized antigen concentration of $1 \mu \mathrm{g} / \mathrm{ml}$, and anti-human IgG diluted at 1:4000.
\end{abstract}

Results: The cut-off optical density value was set as the mean +2 standard deviations (0.54), which resulted in the test having a sensitivity of $88.89 \%$ and a specificity of $95.51 \%$. The recombinant antigen could react with antibodies from $P$. heterotremus, P. pseudoheterotremus and P. westermani infections. Cross-reactivity occurred with a few cases of Blastocystis hominis infection (2/3), Bancroftian filariasis (1/10), opisthorchiasis (3/10), strongyloidiasis (4/10) and neurocysticercosis (1/11).

Conclusions: Given the high test sensitivity and specificity, reflected in the low level of heterologous infection crossreactivity (11/215 serum samples), observed in the IgG-ELISA, this $35 \mathrm{kDa}$ antigen may be useful for the detection of paragonimiasis.

Keywords: Paragonimus heterotremus, cDNA library, Recombinant protein, Paragonimiasis, Immunodiagnosis, IgG-ELISA

\footnotetext{
* Correspondence: paron.dek@mahidol.edu

'Department of Helminthology, Faculty of Tropical Medicine, Mahidol

University, Bangkok 10400, Thailand

Full list of author information is available at the end of the article
}

(c) The Author(s). 2018 Open Access This article is distributed under the terms of the Creative Commons Attribution 4.0 International License (http://creativecommons.org/licenses/by/4.0/), which permits unrestricted use, distribution, and reproduction in any medium, provided you give appropriate credit to the original author(s) and the source, provide a link to the Creative Commons license, and indicate if changes were made. The Creative Commons Public Domain Dedication waiver (http://creativecommons.org/publicdomain/zero/1.0/) applies to the data made available in this article, unless otherwise stated. 


\section{Background}

Paragonimus species, also known as lung flukes, are the causative agents of pulmonary paragonimiasis in humans. In Asia, the occurrence of paragonimiasis is $90 \%$, with about 20 million individuals infected [1, 2]. Seven species of the genus Paragonimus have been recorded in Thailand: P. bangkokensis, P. harinasutai, P. heterotremus, $P$. pseudoheterotremus, $P$. siamensis, $P$. westermani, and $P$. macrorchis. Of these, $P$. heterotremus, $P$. pseudoheterotremus and probably $P$. westermani are reported in human cases [3-5]. People become infected with Paragonimus parasites when they frequently eat improperly cooked freshwater crabs containing Paragonimus metacercariae collected from mountainous streams.

Several suspected cases of paragonimiasis have been clinically identified without the detection of Paragonimus eggs or worms in the sputum, feces, or tissues. Notably, the ectopic foci of this worm in various host tissues can result in cerebral, cutaneous and other clinical forms of paragonimiasis that can be difficult to diagnosis. Therefore, immunodiagnosis is an important supplement to the parasitological methods used in the detection of Paragonimus infections [6, 7]. Specifically, immunoblotting tests using $P$. heterotremus crude extracts of adult worms show high sensitivity and specificity to paragonimiasis heterotremus with diagnostic bands corresponding to $32.5,33$, and $35 \mathrm{kDa}$ native antigens [8] and can differentiate between $P$. heterotremus and $P$. westermani Korean strain [9]. Another $P$. heterotremus component, a $31.5 \mathrm{kDa}$ partially purified antigen, also has been used in the diagnosis of human paragonimiasis [10]. Molecular techniques have been applied as a tool for producing recombinant protein antigens to replace the native antigens produced by other parasitic worm species from animal hosts in similar tests [11]. Obtaining Paragonimus adult worms for native antigen preparation is a very time-consuming and costly process which involves crab collection, recovery of metacercariae from crabs, infecting and maintaining mammalian definitive hosts, confirming infections by eggs detection, and finally obtaining worms from host lungs and processing them for diagnostic testing. Therefore, the aim of the present study was to apply a molecular approach to generate $P$. heterotremus DNA recombinant antigens for use in immunodiagnosis of human paragonimiasis. To this end, we constructed a complementary DNA (cDNA) library from adult $P$. heterotremus worms and used a molecular cloning approach to identify and express recombinant proteins that exhibited selective immunoreactivity with antibodies recognizing the $32.5,33$ and $35 \mathrm{kDa}$ bands comprising $P$. heterotremus native antigens. Herein we report the DNA cloning, identification and expression of a recombinant protein for the $35 \mathrm{kDa}$ antigen and the construction of an IgG-ELISA (enzyme-linked immunosorbent assay) based on this protein. Results of testing against a panel of human sera indicate that the recombinant protein generated by this study may be useful in the serodiagnosis of human paragonimiasis.

\section{Methods \\ Worm collection}

The metacercariae were recovered from freshwater crabs (Larnaudia larnaudii), which were collected from paragonimiasis endemic areas of Nakon Nayok Province, central Thailand. Gerbils were infected by feeding five fresh metacercariae to each animal using a stomach tube connected to a syringe and maintained for at least 35 days, at which time $P$. heterotremus eggs were observed in the feces using a simple smear technique. Gerbils were then euthanized and the adult worms isolated from the lungs and surrounding lung tissues. Isolated worms were washed 3 times in $0.85 \%$ sterile $\mathrm{NaCl}$ and used for preparing crude antigen and for isolation of total worm RNA.

\section{Construction and immunoscreening of the cDNA library}

To construct the cDNA, total RNA was extracted from fresh $P$. heterotremus adult worms by using the singlestep method of total RNA extraction with $\mathrm{TRIzol}^{\circledR}$ reagent (Invitrogen-Life Technologies, Carlsbad, CA, USA). Messenger RNA (mRNA) was isolated using a solid-phase oligo-dT matrix (Oligotex mRNA mini kit; Qiagen, Hilden, Germany) according to the manufacturer's instructions. Two micrograms of mRNA template was used in the Universal RiboClone ${ }^{\curvearrowleft}$ cDNA Synthesis System (Promega, Madison, WI, USA) and further ligated into a pJET 1.2/blunt Cloning Vector (CloneJET PCR Cloning Kit, Thermo Fisher Scientific, Rockford, IL, USA). The ligation mixture was used directly to transform Escherichia coli XL1-Blue (Stratagene, Agilent Technologies, Santa Clara, CA, USA) competent cells, followed by plating on LB agar plates supplemented with ampicillin for Ampicillin-selection. To identify the antigen-producing clones by immunoscreening, the pooled negative (pre-immunized sera) and positive sera from mice that had been immunized with the crude eluted $32.5,33$ and $35 \mathrm{kDa}$ antigens of $P$. heterotremus were used to identify clones carrying the 32.5, 33 and 35 $\mathrm{kDa}$ antigens. Positive colonies were identified by aligning the membrane with the agar plates. For DNA sequencing, the PCR was performed by using pJET 1.2 forward and PJET 1.2 reverse sequencing primers. The resulting gene sequences were searched against the NCBI database.

\section{Target sequence amplification}

The protein targets for DNA cloning were selected based on the results of immunoscreening tests, aimed to extend the target sequences. The L_2F was selected as 
target clone. The designed primers were: $\mathrm{Ph} 3$ forward primer 5'-CTC TAG AAG ATC TCC TAC-3' and Ph3 reverse primer 5'-AGC CGA ACG ACC GAG CGC-3'. After PCR amplification, the PCR product was further purified. The purified DNA was cloned, designated clone CE3, by using a StrataClone PCR Cloning kit (Stratagene, Agilent Technologies), according to the manufacturer's instructions.

\section{Construction of a recombinant protein clone Plasmid creation}

Primers for clone CE3 were designed based on the DNA sequencing results. These include: CE3 forward primer, 5'-CGA ACG TCG AGC GCT TAC TGT GAC A-3', which contained XhoI restriction enzyme sites, and CE3 reverse primer, 5'-AGC CGA GAA TTC GAG CGC CTT GCA AAA G-3', which contained EcoRI restriction enzyme sites. To amplify the target protein, PCR was performed as described above. Both the pRsetB vector (Invitrogen Ltd., Paisly, UK) and the purified DNA were digested with XhoI and EcoRI restriction enzymes using the Fermentas FastDigest Restriction Enzymes kit (Thermo Fisher Scientific). Finally, ligation was performed, and the obtained plasmid was transformed into E. coli host cells (strain DH5 $\alpha$ or strain DE3 BL21 pLysS).

\section{Protein expression and purification of the recombinant protein}

A single colony of CE3 protein-expressing host cells was inoculated in a tube that contained LB broth with ampicillin and chloramphenicol and further incubated overnight at $37{ }^{\circ} \mathrm{C}$ with shaking at $180 \mathrm{rpm}$ (New Brunswick Scientific Innova ${ }^{\oplus} 40$, Edison, NJ, USA). The cultured cells were then inoculated into ampicillin-chloramphenicol LB broth and shaken at $37{ }^{\circ} \mathrm{C}$ for $3 \mathrm{~h}$. IPTG (1 mM isopropyl-lthio- $\beta$-D-galactopyranoside) was added to induce protein expression and shaken at $180 \mathrm{rpm}$ for an additional $4 \mathrm{~h}$ at $37{ }^{\circ} \mathrm{C}$. The cultured cells were centrifuged for the pellet and stored at $-70{ }^{\circ} \mathrm{C}$ until required.

Following recombinant protein induction, host cells were pelleted and then extracted by suspending cells in BugBuster $^{\mathrm{rm}}$ (Novagen $^{\mathrm{Tm}}$, Merck, Darmstadt, Germany). The extract mixture was centrifuged for collecting the supernatant containing solubilized proteins. The putative recombinant His6 (Histidine 6) fusion protein was then purified using a Ni-NTA (nickel-nitrilotriacetic acid) chromatography column according to the manufacturer's instructions (Ni-NTA ProBond, Invitrogen, USA). Eluted fractions were collected and checked by SDSPAGE analysis for the desired protein. Eluted fractions that possessed a single protein band were pooled, subjected to dialysis, and lyophilization.

\section{Immunoreactivity of purified recombinant proteins to sera of immunized mice}

Three mice were each injected via the intraperitoneal route (IP) with $1 \mu \mathrm{g}$ of the $35 \mathrm{kDa}$ recombinant protein, mixed 1:1 with Inject ${ }^{\oplus}$ Alum (Thermo Fisher Scientific). Mice were given IP booster injections with the same dose twice more at 2-week intervals. Blood samples were collected at 1 week after the last injection, and the resulting sera were tested against each recombinant protein antigen by Western blot analyses.

\section{Evaluation of recombinant proteins for serodiagnosis of paragonimiasis heterotremus Human sera}

The collection of patients' sera used as the diagnostic test panel in the present study was stored specimens that had been used in the previous serological surveys. All samples had been maintained at $-80{ }^{\circ} \mathrm{C}$ in the Department of Helminthology, Faculty of Tropical Medicine, Mahidol University for several years, and contained no patient identifying information (see Ethical Approval and Consent section). Details of the diseases and corresponding diagnostic methods used on the groups of serum samples (Group A: paragonimiases, Group B: other parasitic infections and Group C: healthy controls) for the evaluation of the recombinant antigens are shown in Table 1.

\section{Enzyme-linked immunosorbent assay (ELISA)}

An indirect ELISA was created based on the recombinant $35 \mathrm{kDa}$ protein antigen and was evaluated using groups of sera from patients infected with paragonimiases $(n=36)$, heterologous infections $(n=215)$ and healthy controls $(n=30)$. The ELISAs were performed as described by Dekumyoy et al. [8] with minor modifications. Single serum dilutions, 1:2000, of individual positive and negative sera against $1 \mu \mathrm{g} / \mathrm{ml}$ purified recombinant antigen were performed to establish the optimal conditions for the tests. In addition, 1:4000-diluted horseradish peroxidase-conjugated rabbit anti-human IgG (Southern Biotech, Birmingham, USA) and colormetric substrate solution [ABTS, 2, 2-azino-di-(3-ethylbenzthiazoline sulfonate); Sigma, Oakville, Ontario, Canada] were used. The reactions were stopped by adding $50 \mu \mathrm{l}$ of $1 \%$ SDS solution. Antigen-antibody binding reactions were measured by reading the $\mathrm{OD}_{405}$ (optical density) using an ELISA Reader (Tecan, Männedorf, Switzerland).

\section{Data analysis}

The ELISA cut-off point was chosen by using receiver operating characteristic (ROC) curve analysis, sensitivity versus 1 -specificity or false positive. The SPSS version 18 was used as tool for ROC curve analysis. All data were 
Table 1 Diseases, and corresponding diagnostic methods, detected in the serum samples

\begin{tabular}{|c|c|c|c|}
\hline Group & Diseases & $\begin{array}{l}\text { No. of } \\
\text { serum } \\
\text { samples }\end{array}$ & Diagnostic methods \\
\hline \multirow[t]{4}{*}{ A } & $\begin{array}{l}\text { Paragonimiasis } \\
\text { heterotremus }\end{array}$ & 29 & $\begin{array}{l}\text { Worm and egg detection, } \\
\text { serum samples collected for } \\
\text { over } 25 \text { years, patients resided } \\
\text { in } 2 \text { endemic provinces of } P \text {. } \\
\text { heterotremus in the central } \\
\text { Thailand where metacercariae } \\
\text { from crabs were identified by } \\
\text { PCR a few years ago }\end{array}$ \\
\hline & $\begin{array}{l}\text { Paragonimiasis } \\
\text { pseudoheterotremus }\end{array}$ & 3 & $\begin{array}{l}\text { Eggs in feces and PCR ( } 1 \text { case), } \\
\text { immunoblot detection and } \\
\text { PCR for detection of } \\
\text { metacercariae from crabs ( } 2 \\
\text { cases). Patients resided along } \\
\text { Thai-Myanmar border }\end{array}$ \\
\hline & $\begin{array}{l}\text { Paragonimiasis } \\
\text { westermani }\end{array}$ & 4 & $\begin{array}{l}\text { Serum samples were } \\
\text { supported by Korean } \\
\text { researcher }\end{array}$ \\
\hline & Total & 36 & \\
\hline \multirow[t]{23}{*}{ B } & Gnathostomiasis & 10 & $\begin{array}{l}\text { Worm and immunoblot } \\
\text { detection }\end{array}$ \\
\hline & Strongyloidiasis & 10 & Larva detection \\
\hline & Hookworm infection & 10 & Egg detection \\
\hline & Trichinellosis & 10 & $\begin{array}{l}\text { Larva and immunoblot } \\
\text { detection }\end{array}$ \\
\hline & Capillariasis & 3 & $\begin{array}{l}\text { Egg, larva, adult worm } \\
\text { detection }\end{array}$ \\
\hline & Toxocariasis & 10 & Immunoblot \\
\hline & Angiostrongyliasis & 10 & Worm detection, immunoblot \\
\hline & Ascariasis & 6 & Egg and worm detection \\
\hline & Trichuriasis & 9 & Egg and worm detection \\
\hline & Trichostrongyliasis & 10 & Egg detection \\
\hline & Bancroftian filariasis & 10 & Microfilariae detection \\
\hline & Enterobiasis & 4 & Egg and worm detection \\
\hline & Brugian filariasis & 10 & Microfilariae detection \\
\hline & Brugian filariasis & 10 & $\begin{array}{l}\text { ELISA using recombinant } \\
\text { antigen }\end{array}$ \\
\hline & Dirofilariasis & 2 & Worm detection \\
\hline & Neurocysticercosis & 11 & Cyst detection, immunoblot \\
\hline & Sparganosis & 6 & Sparganum detection \\
\hline & Taeniasis & 13 & $\begin{array}{l}\text { Egg or segments ( } T \text {. solium or } \\
\text { T. saginata) }\end{array}$ \\
\hline & Echinococcosis & 3 & Protoscolices detection \\
\hline & $\begin{array}{l}\text { Hymenolepiasis } \\
\text { nana }\end{array}$ & 5 & Egg detection \\
\hline & $\begin{array}{l}\text { Hymenolepiasis } \\
\text { diminuta }\end{array}$ & 1 & Egg detection \\
\hline & Opisthorchiasis & 10 & Worm detection \\
\hline & $\begin{array}{l}\text { Echinostomiasis } \\
\text { malayanum }\end{array}$ & 1 & Egg detection and PCR \\
\hline
\end{tabular}

Table 1 Diseases, and corresponding diagnostic methods, detected in the serum samples (Continued)

\begin{tabular}{|c|c|c|c|}
\hline Group & Diseases & $\begin{array}{l}\text { No. of } \\
\text { serum } \\
\text { samples }\end{array}$ & Diagnostic methods \\
\hline & Fascioliasis & 3 & Egg detection, immunoblot \\
\hline & $\begin{array}{l}\text { Minute intestinal } \\
\text { flukes infections }\end{array}$ & 10 & Worm detection \\
\hline & Creeping eruption & 3 & $\begin{array}{l}\text { Symptoms, negative for } \\
\text { strongyloidiasis and } \\
\text { gnathostomiasis }\end{array}$ \\
\hline & Entamebiasis & 4 & Cyst detection \\
\hline & Giardiasis & 3 & Cyst detection \\
\hline & $\begin{array}{l}\text { Blastocyctis hominis } \\
\text { infection }\end{array}$ & 3 & Cyst detection \\
\hline & Falciparum malaria & 5 & Blood stage detection \\
\hline & Vivax malaria & 5 & Blood stage detection \\
\hline & Tuberculosis & 5 & $\begin{array}{l}\text { Acid fast stained } \\
\text { Mycobacterium tuberculosis }\end{array}$ \\
\hline & Total & 215 & \\
\hline C & Healthy serum & 30 & $\begin{array}{l}\text { Negative ELISA using ten kinds } \\
\text { of antigens and fecal } \\
\text { examinations }\end{array}$ \\
\hline & Total & 30 & \\
\hline
\end{tabular}
healthy controls

further analyzed by using the Mann-Whitney U-test. The calculation was carried out on SPSS version 18 and a $P$-value $<0.05$ was considered as significant. The accuracies of the diagnostic test, including sensitivity, specificity, and predictive values, were determined using the method of Parikh et al. [12] and SPSS version 18 and MedCal (free statistical calculators, diagnostic test evaluation calculator) were used at 95\% CI. The ELISAs were analyzed by calculating the means and standard deviations (SD). A cut-off value at 0.543 was done by ROC curve analysis and the mean + 2SD. The AUC was 0.975.

\section{Results \\ Isolation of total RNA, purification of mRNA, and construction of a $P$. heterotremus CDNA library}

A double-stranded $P$. heterotremus cDNA reaction was run on a $1.2 \%$ agarose gel along with a $1 \mathrm{~kb}$ DNA size marker. The sizes of the cDNA bands ranged from 0.5 to $12 \mathrm{~kb}$. After the cDNA was purified by using Promega Wizard $^{\circ}$ DNA Clean-UP System (Promega, Madison, WI, USA), the double-stranded cDNA was successfully ligated into the PJET 1.2/blunt cloning vector and used to transform in E. coli XLI Blue on LB agar. In order to check the size of inserts, 14 colonies were randomly picked and PCR was performed. The sizes of insert cDNAs, as determined by performing colony PCR, ranged from approximately 500 to $1000 \mathrm{bp}$ (Additional file 1: Figure S1). The products of the positive clones 
that were larger than 500 bp were further assessed by colonies amplification and sequencing.

\section{Sequence analysis}

We determined the DNA sequences of each of the 11 plasmid clones described above, the insert sizes of which ranged from 500 to $1000 \mathrm{bp}$. Homology searches against NCBI databases (https://www.ncbi.nlm.nih.gov/) revealed some clones matched were a trematode group i.e. clone IDs, P89-1, P51-R, P55-R, P3_1F. The identities of these matches are listed in Table 2, and the percentage of identity of these eleven clones ranged from 31 to $100 \%$ when searched against the trematodes, bacteria and protozoans in the NCBI database.

\section{PCR confirmatory test and DNA cloning}

After the initial cloning described above, the inserted cDNA that was $>500$ bp in size was run on a $1.2 \%$ agarose gel. The band containing the inserted cDNA was then cut and purified for further second cloning to extend sequences. Eleven plasmid clones were identified by immuno-screening of the cDNA library. The inserted cDNA from clone L_2F (designated CE3) was run on a $1.2 \%$ agarose gel, and based on comparison with the Kapa Universal ladder, was approximately 900 bp long (Additional file 2: Figure S2). The CE3 clone was selected as representative of the antigenic clones since it possessed the longest sequence that contained no stop codons.

\section{Sequence analysis}

After the DNA sequences were checked for open reading frames and stop codons, clone number 3 (CE3) was chosen for recombinant protein production since CE3 was given the similar identity of sequences to other clones and had a long sequence without stop codon between the sequences. Specific primers were used to amplify the DNA via PCR. A sequence analysis of the recombinant protein from clone $\mathrm{CE} 3$ and the corresponding alignment scores calculated by the NCBI-Blastx program show that it shares identity with the proactivator polypeptides of $C$. sinensis and Schistosoma haematobium at 48 and 29\%, respectively (Table 3). An overview of the CE3 clone using DNAMan software consists of 1292 bp with an open reading frame at 49-1047 bp (Additional file 3: Figure S3), under the accession number KX180136, and the estimated molecular weight of the corresponding protein is $35 \mathrm{kDa}$ (Fig. 1).

\section{IPTG-induced protein expression and purification of recombinant proteins}

We examined the effect of IPTG-induction on recombinant protein expression. The IPTG-induction was started from $0 \mathrm{~h}$ (non-IPTG-induced) to $3 \mathrm{~h}$ (IPTG-induced); proteins were observed every hour. The protein expression was increased following timing. Whole bacterial lysates from non-IPTG-induced and IPTG-induced CE3 clones at $3 \mathrm{~h}$ were analyzed by SDS-PAGE in a $12 \%$ polyacrylamide gel and stained with Coomassie brilliant blue. After IPTG induction for $3 \mathrm{~h}$, there was an increase in the amount of an expressed $35 \mathrm{kDa}$ protein (Fig. 1), indicating that the fusion protein from clone CE3 was successfully expressed in E. coli upon IPTG induction.

After extraction of bacterial cells with BugBuster ${ }^{\text {ra }}$ and centrifugation and washes with lysis buffer (8M urea in LEW buffer), the crude recombinant protein extract was subjected to passage through a nickel-agarose affinity column, followed by elution with buffer containing various concentrations of imidazole ranging from 100 to $500 \mathrm{mM}$. A SDS-PAGE analysis of the purified protein fractions eluted at imidazole concentrations of 25, 50, 100, 200 and $500 \mathrm{mM}$ showed the expected enrichment of the $35 \mathrm{kDa}$ band in the eluted fractions. The isolated fractions recovered from the 100, 200 and $500 \mathrm{mM}$ imidazole elutions were then pooled and dialyzed against $0.1 \times$ PBS (phosphate buffered saline-Tween20 buffer, $\mathrm{pH}$ 7.2) for further use.

Table 2 The sequence analysis results after being searched against NCBI databases

\begin{tabular}{llll}
\hline Sample No. & Clone ID & Name & Percentage of identity \\
\hline 1 & P89-1 & Fatty acid-binding protein type 3 (Clonorchis sinensis) & 70 \\
2 & P51-F & Microcystin synthetase (uncultured Microcystis sp.) & 73 \\
3 & P51-R & Dynein beta Chain ciliary (C. sinensis) & 97 \\
4 & P55-R & Hypothetical proteinSMP_137720 (Schistosoma mansoni) & 31 \\
5 & P3_1F & SJCH6C65074 protein (Schistosoma japonicum) & 78 \\
6 & P7_2UF & Histone lysine methyltransferases (Toxoplasma gondii) & 43 \\
7 & L_2F & Hypothetical protein (Echinococcus multilocularis) & 92 \\
8 & L_3R & Axonemal beta dynein heavy chain, putative (T. gondii ME49) & 37 \\
9 & L_2F2 & Hypothetical protein (Plasmodium chabaudi chabaudi) & 99 \\
10 & L_8F & Protein Bm11556, partial (Brugia malayi) & 100 \\
\hline
\end{tabular}




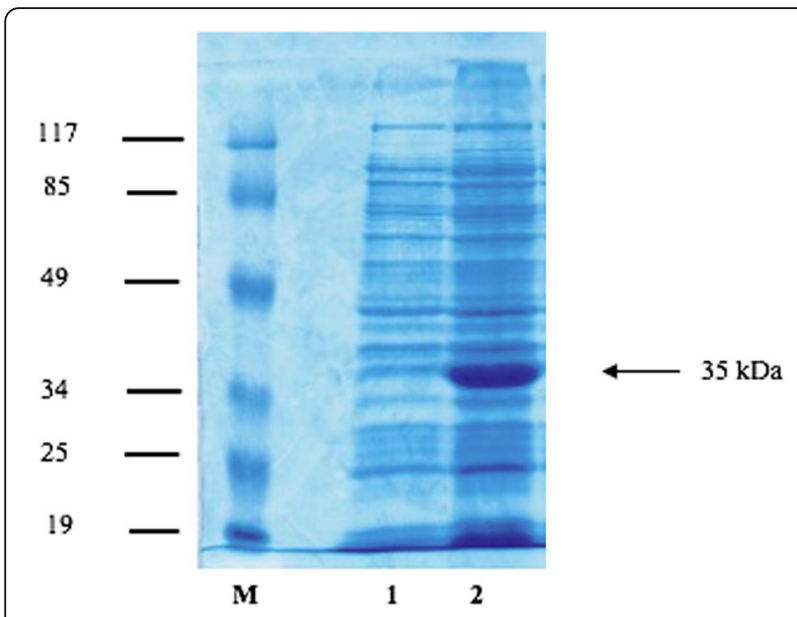

Fig. 1 Assessment of recombinant fusion protein production in CE3-clone transformed E. coli cells. The proteins from these cells were separated on a $12 \%$ gel by SDS-PAGE and stained with Coomassie blue. Lane M: molecular weight markers; Lane 1: non-IPTG-induced CE3 cells; Lane 2: IPTG-induced CE3 cells. Arrow indicates the prominent band at $35 \mathrm{kDa}$

\section{Mouse immunization with the $35 \mathrm{kDa}$ recombinant protein}

After isolation, the $35 \mathrm{kDa}$ purified recombinant protein was used to immunize mice for specific antibody production. ELISAs were performed against the purified recombinant protein. The mouse antibody against the $35 \mathrm{kDa}$ recombinant protein had titer over 1:1600. Additionally, using Western blot analysis, the $35 \mathrm{kDa}$ recombinant protein from the CE3 clone also was recognized by the antibodies in the sera of immunized mice, but not by sera from normal, unimmunized mice (Fig. 2).

\section{Serodiagnostic evaluation of the $35 \mathrm{kDa}$ recombinant protein by ELISA}

An indirect ELISA was developed using the $35 \mathrm{kDa}$ recombinant protein and sera from healthy controls or from patients with human paragonimiasis or other parasitic infections (Table 1) were used to assess the specificity and sensitivity of this assay as an immunodiagnostic tool. The ELISA conditions were optimized by fixing the concentration of the secondary antibody at a 1:4000 dilution and then optimizing the primary antibody and recombinant protein concentrations. As a result, in subsequent assays, the primary antibodies (human sera) were diluted to 1: 2000 , and $1 \mu \mathrm{g} / \mathrm{ml}$ of recombinant protein was used to coat wells of ELISA plates. Based on the ELISA results from 30 negative serum samples, the cut-off value was selected from the mean $\pm 2 \mathrm{SD}$ at $\mathrm{OD}_{405}=0.54$. Evaluating the IgGELISA with this cut-off value produced sensitivity, specificity, and positive and negative predictive values at 88.89 , 95.51, 74.42 and 98.32\%, respectively (Table 4) (calculated by MedCal with $95 \% \mathrm{CI}$ ). Based on this $\mathrm{OD}_{405}$ cut-off value of $0.54,32$ of 36 serum samples from patients with confirmed paragonimiasis gave positive assay results. The 4 false negative sera, although below the 0.54 OD threshold, were not far from the cut-off value. Regarding to paragonimiasis, this recombinant antigen strongly react with serum antibodies from 3 cases of paragonimiasis pseudoheterotremus and 2 cases of paragonimiasis westermani in the high ODs-ranges, 0.856-1.145 and 0.799-0.853, respectively. The antigen weakly reacted with antibodies from tuberculosis. Importantly, this recombinant antigenic protein resulted in true negative readings for sera representing 27 of 32 different parasitic diseases, as well as for all negative controls. Cross-reactivity occurred for five diseases (11/ 215 serum samples), including Blastocystis hominis infection (2/3), Bancroftian filariasis (1/10), opisthorchiasis (3/ $10)$, strongyloidiasis (4/10), and neurocysticercosis (1/11). We observed that one of four false positives for strongyloidiasis gave a quite high OD-value, above the cutoff value. The OD-values of false positives from Blastocystis hominis infection, Bancroftian filariasis, neurocysticercosis and opisthorchiasis were close to the cut-off value (Fig. 3).

\section{Statistical analysis}

All data were analyzed by SPSS version 18 and were found to be non-parametric. A value of $\mathrm{P}<0.0001$ was considered as significant (Wilcoxon signed-rank test: $Z=30365.000$, Mann-Whitney U-test: $U=230, Z=-9.306, P<0.0001$ ). The statistical results indicated that there was a significant difference between paragonimiasis samples and nonparagnimiasis samples, heterologous infected groups and healthy control. Moreover, the median scores of the paragonimiasis and non-paragonimiasis groups were 257.78 and 123.94 , respectively.

Table 3 Alignment score of the putative amino acid sequences of the $35 \mathrm{kDa}$ antigen as calculated by the NCBI-BLASX program from clone CE3

\begin{tabular}{lllll}
\hline Accession No. & Sequence description & Identity (\%) & Score (Bits) & E-value \\
\hline GAA56617.1 & Proactivator polypeptide (Clonorchis sinensis) & 48 & 297 & $4 \mathrm{E}-92$ \\
XP_012799469.1 & Proactivator polypeptide (Schistosoma haematobium) & 29 & 197 & $3 \mathrm{E}-34$ \\
AAW27625.1 & SJCHGC01869 protein (Schistosoma japonicum) & 28 & 237 & $1 \mathrm{E}-31$ \\
CCD59012.1 & Saposin-containing protein (Schistosoma mansoni) & 27 & 245 & $1 \mathrm{E}-31$ \\
\hline
\end{tabular}




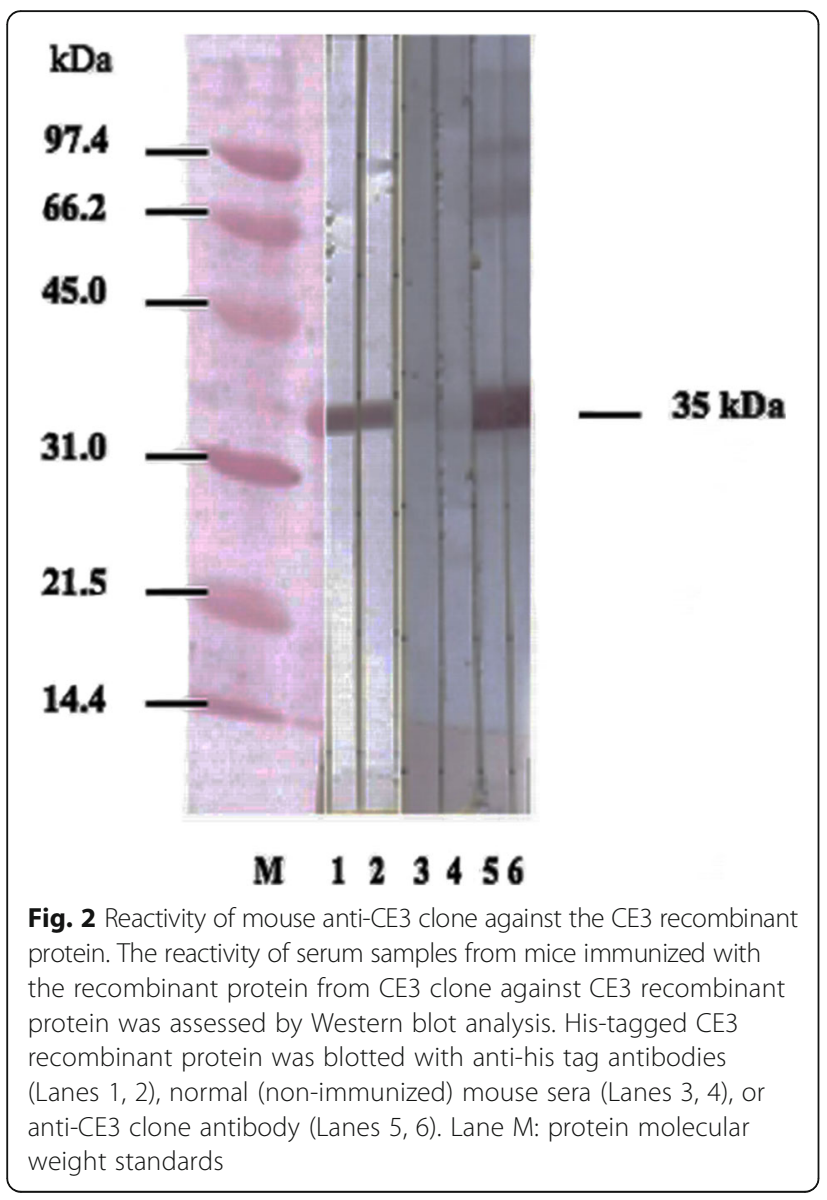

\section{Discussion}

In the present study, a novel recombinant protein antigen was produced from a cloned cDNA of $P$. heterotremus worms, designated CE3. This insert cDNA sequence exhibited closest homology to a proactivator polypeptide of the liver fluke, Clonorchis, and the encoded a protein antigen that specifically reacted to antibodies directed against the specific $35 \mathrm{kDa}$ diagnostic band seen in native adult worm antigen extracts. The IgG-ELISA used to evaluate this recombinant protein yielded sensitivity, specificity, and positive and negative predictive values of $88.89,95.51$, 74.42 and $98.32 \%$, respectively, and resulted in false positives for only four helminthic infections and one protozoan infection. Specificity of the test using this recombinant antigen is quite high, which was evaluated against 32 different diseases as indicated above. It should be noted by including serum samples from patients infected with the three human Paragonimus spp: P. heterotremus, $P$. pseudoheterotremus and $P$. westermani, we found that the ELISA was not able to discriminate between species-specific infections. However, given the similarities in infection transmission, clinical disease and treatment options for these lung fluke infections, having a broad-based diagnostic for human paragonimiasis, regardless of the species, provides a valuable tool for infection screening and/or diagnoses. The expressed recombinant $P$. heterotremus protein (CE3), when incorporated into the ELISA immunoassay, not only exhibited the expected high specificity to antibodies from mice immunized with the recombinant $35 \mathrm{kDa}$ protein, but also showed positive reactive and high specificity to antibodies from 32 of 36 human paragonimiasis serum samples. As noted, the other four paragonimiasis sera produced the OD-values close to the cut-off point. Antibody cross-reactivity is largely related to the presence of helminth protein epitopes that are shared in common with similar proteins from other parasite species resulting in a false positive test outcome, or the individual donor may have been previously infected with lung flukes. However, only a few cases of other parasitic diseases, opisthorchiasis, strongyloidiasis, Bancroftian filariasis, neurocysticercosis and B. hominis infection cross-reacted with the proactivator polypeptide recombinant antigen. Considering location of these parasites in patients, as is generally known, $B$. hominis is an intestinal protozoan and mostly asymptomatic, Opisthorchis viverrini is located in the bile duct and Wuchereria bancrofti is located in the lymphatic. Symptoms typically seen in infections by all three of these parasites are quite different from lung fluke infections, and therefore, can be more easily diagnosed based on clinical presentations. However,

Table 4 Cut-off values, sensitivity, specificity, and positive and negative predictive values of the $P$. heterotremus $35 \mathrm{kDa}$ recombinant fusion protein ELISA. The ELISA was performed using $1 \mathrm{\mu g}$ of $P$. heterotremus $35 \mathrm{kDa}$ recombinant fusion protein and 30 negative serum samples diluted at 1:2000. Test results were determined by the $\mathrm{OD}_{405}$ values of all serum samples under the cut-off value of 0.54

\begin{tabular}{|c|c|c|c|c|c|}
\hline \multirow[t]{2}{*}{ Cut-off value } & \multirow{2}{*}{$\begin{array}{l}\text { OD } \\
\text { at } \\
405 \\
\mathrm{~nm}\end{array}$} & \multirow{2}{*}{$\begin{array}{l}\text { Sensitivity } \\
(\%)\end{array}$} & \multirow{2}{*}{$\begin{array}{l}\text { Specificity } \\
(\%)\end{array}$} & \multicolumn{2}{|c|}{ Predictive values (\%) } \\
\hline & & & & Positive & Negative \\
\hline Mean + SD & 0.44 & 80 & 80 & 80 & 80 \\
\hline Mean + 2 SD & 0.54 & 100 & 100 & 100 & 100 \\
\hline Mean + 3 SD & 0.64 & 0 & 100 & 0 & 50 \\
\hline \multicolumn{6}{|c|}{ Evaluation of test under the cut-off value in this study } \\
\hline Mean +2 SD & 0.54 & 88.89 & 95.51 & 74.42 & 98.32 \\
\hline
\end{tabular}




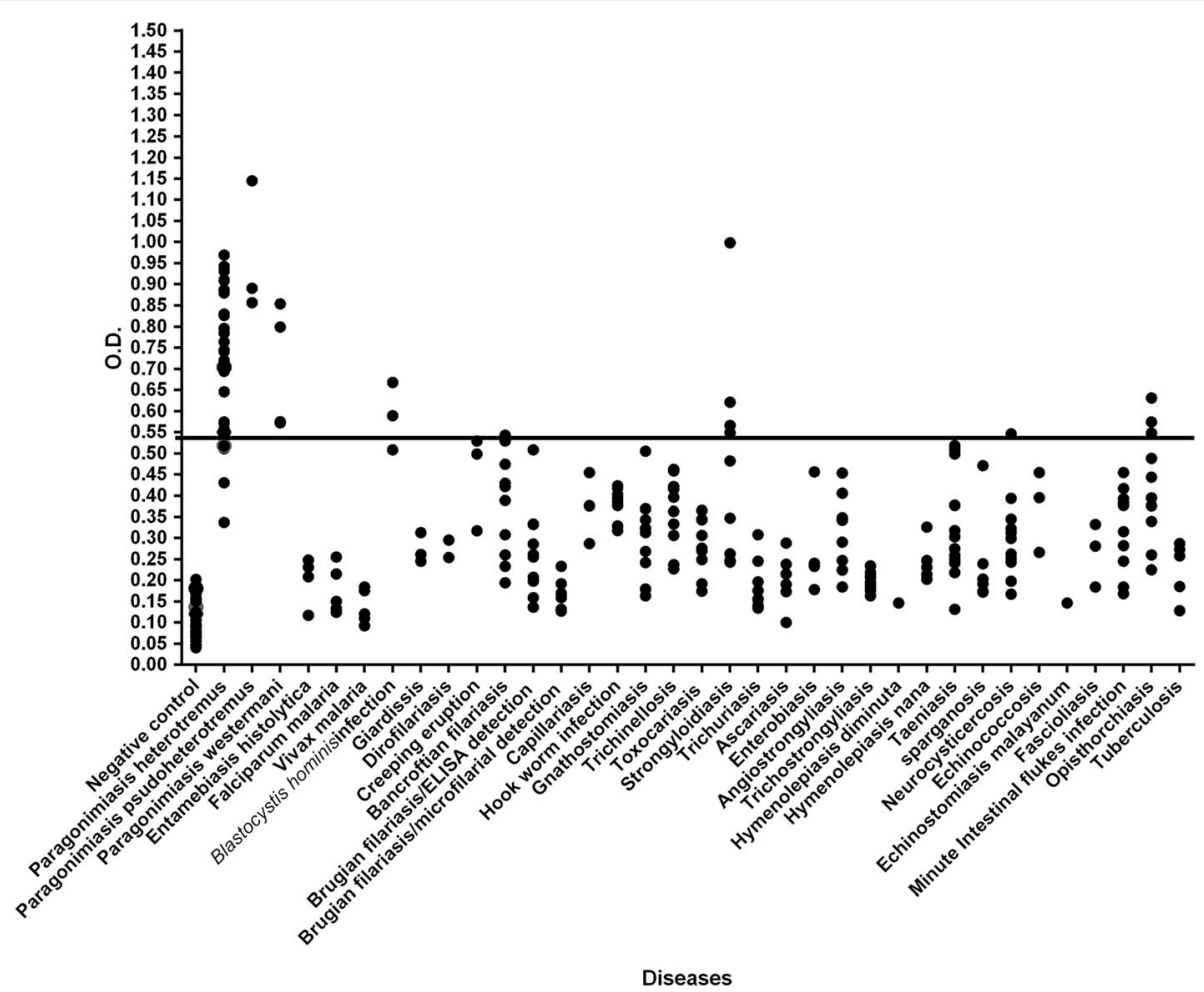

Fig. 3 Scatter pattern of ELISA absorbance values was developed by using purified recombinant antigen, and the specificity of this assay was assessed using serum samples from paragonimiasis patients, healthy human controls (negative control) and patients with various parasitic and bacterial diseases (cut-off at a mean $+2 \mathrm{SD}=0.54$ )

S. stercoralis larvae pass the lungs during their development before moving to the intestine to become adult worms, but most OD-values were lower than the cut-off value. The serum sample exhibiting cross-reactivity above the cut-off may be a result from a co-infection with Paragonimus because it has been previously shown [8] that antibodies produced in naturally-acquired opisthorchiasis, strongyloidiasis, and neurocysticercosis do not react with $35 \mathrm{kDa}$ antigen of adult $P$. heterotremus worm. We noted in the study of Yoonuan et al. [13] that antibody crossreactivity of opisthorchiasis, ascariasis and strongyloidiasis also occurs in IgG-ELISA using $35 \mathrm{kDa}$ cathepsin L lacking signal peptide (rPpsCatL, recombinant $P$. pseudoheterotremus cathepsin L). However, although both the proactivator polypeptide (current study) and the cathepsin $\mathrm{L}$ proteins share a similar $35-\mathrm{kDa}$ molecular mass, both appear antigenically distinct based on differences in their immunoreactivity profiles. Also our antigen did not crossreact with ascariasis patient sera, further distinguishing it from the recombinant cathepsin $\mathrm{L}$.

It is known that serodiagnosis can play an important role as a supplementary method of human paragonimiasis diagnosis. An ELISA is a complementary method for diagnosis of cerebral paragonimiasis, chronic cerebral paragonimiasis, pulmonary and ectopic pulmonary paragonimiasis [14, 15]. In 1991, Indrawati et al. [6] produced a partially purified adult worm antigen of $P$. heterotremus using Sephadex column chromatography and subsequently used this antigen preparation in the serodiagnosis of human paragonimiasis heterotremus. The IgG-ELISA constructed using this antigen showed $100 \%$ sensitivity and $100 \%$ specificity (seven diseases). A partially purified antigen has been prepared from adult worms of $P$. heterotremus using an isoelectric focusing cell (Rotofor, Bio-Rad, Hercules, California, USA). This partially purified antigen shows a specific antigen at $31.5 \mathrm{kDa}$, which gave ELISA values, 100\% sensitivity and 99\% specificity (12 diseases). Only one of fascioliasis showed a false positive [10]. Besides, enzymes in the excretory-secretory products of lung flukes can also be useful in the serodiagnosis of paragonimiasis westermani, as shown for cysteine protease antigens in an IgG-ELISA [16]. In another study was a chicken cystatin capture ELISA for detection of antibodies to $P$. westermani. In this assay, the cystatin binds with fluke cysteine proteinases in excretorysecretory products, and then is exposed to sera from paragonimiasis patients containing antibodies to the cycteine proteases. The paragonimiasis cystatin capture ELISA showed high reactivity [17], although native cysteine proteinases are highly conserved and possess common epitopes that are shared among many Paragonimus species including $P$. westermani, 
P. miyazakii and P. ohirai [16], thereby limiting their immunodiagnostic potential.

In addition to recombinant technology allowing the production of an unlimited amount of antigen, its application in generating a DNA recombinant protein of $P$. westermani eggs resulted in a significant increase in the sensitivity and specificity of an ELISA for paragonimiasis diagnosis to 90.2 and $100 \%$, respectively, and also useful for an epidemiological study of paragonimiasis [18]. A recently developed IgG-ELISA using the recombinant cysteine protease antigen $(21 \mathrm{kDa})$ derived from cDNA of the Paragonimus skrjabini juvenile stage was reported to have a sensitivity of $95.5 \%$ and no cross-reaction with antibodies from the other human diseases in the study by $\mathrm{Yu}$ et al. [19], i.e. echinococcosis granulosus, taeniasis solium, schistosomiasis japonicum and trichinellosis spiralis [19]. Another recombinant antigen is the $35 \mathrm{kDa}$ cathepsin L lacking signal peptide (rPpsCatL), which is produced from the cDNA of $P$. pseudoheterotremus worms and belongs to the cysteine protease group. This rPpsCatL was used in IgG-ELISA for paragonimiasis heterotremus, resulting in 100\% sensitivity and $95.6 \%$ specificity (27 diseases). Cross-reactivity occurred from ten cases of strongyloidiasis, toxocariasis, Brugian filariasis, ascariasis, opisthorchiasis and fascioliasis [13]. Despite the fact that the recombinant antigens used in that study (rPpsCatL) and the current study (proactivator polypeptide) possessed the same molecular weight, the sensitivity and specificity results for their corresponding IgG-ELISAs suggest that they differ in antigenic reactivity to antibodies. However, both of these recombinant antigens were cross-reactive with antibodies from strongyloidiasis and opisthorchiasis. Further studies of the $P$. heterotremus proactivator recombinant antigen could lead to improvements in its diagnostic specificity and sensitivity. For example, identification and immune testing of individual antibody-reactive epitopes through epitope mapping of the protein could lead to highly-specific single-epitope diagnostic testing formats. Currently we are exploring this and other, serodiagnostic tests for the detection of ectopic human paragonimiasis infections.

\section{Conclusions}

In the present study, a novel recombinant protein antigen was produced from the cDNA of $P$. heterotremus worms. This antigen specifically responded to antibody directed against the specific diagnostic band of native $35 \mathrm{kDa}$ antigen. The insert of cDNA is suggested to be homologous to a proactivator polypeptide. The IgG-ELISA was used to evaluate this recombinant protein and this resulted in sensitivity, specificity, and positive and negative predictive values of $88.89,95.51,74.42$ and $98.32 \%$, respectively. False positives were found from only a few cases of four helminthic infections and one protozoan infection. In contrast to diagnoses, symptoms and history of intermediate host consumption are helpful for physicians to predict early stages of disease. However, for clinically unpredicted or suspected cases of paragonimiasis, which may result from immature or mature Paragonimus worms located outside the lungs, serodiagnosis can be of great assistance as an adjunct diagnostic tool. Therefore, the incorporation of the recombinant proactivator polypeptide as a serological test antigen shows promise for the detection of human paragonimiasis.

\section{Additional files}

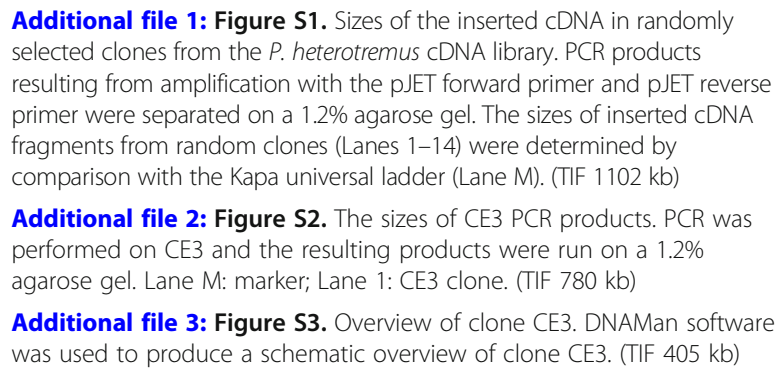

Additional file 2: Figure S2. The sizes of CE3 PCR products. PCR was performed on CE3 and the resulting products were run on a $1.2 \%$ agarose gel. Lane M: marker; Lane 1: CE3 clone. (TIF 780 kb)

Additional file 3: Figure S3. Overview of clone CE3. DNAMan software was used to produce a schematic overview of clone CE3. (TIF $405 \mathrm{~kb}$ )

\begin{abstract}
Abbreviations
ABTS: 2,2-azino-di-(3-ethyl-benzthiazoline sulfonate); AUC: area under the ROC curve; Cl: confidence interval; ELISA: enzyme-linked immunosorbent assay; His6: histidine 6; IgG: immunoglobulin G; IP: intraperitoneal route; IPTG: isopropyl-I-thio- $\beta$-D-galactopyranoside; Ni-NTA: nickel-nitrilotriacetic acid; OD: optical density; PBS: phosphate-buffered saline; ROC: receiver operating characteristic; rPpsCatL: recombinant Paragonimus

pseudoheterotremus cathepsin L; SDS-PAGE: sodium dodecyl sulphatepolyacrylamide gel electrophoresis
\end{abstract}

\section{Acknowledgments}

We would like to thank Dr Tippayarat Yoonuan, Mr Nirundorn Homsuwan and the staff of the Department of Helminthology, Faculty of Tropical Medicine, Mahidol University, Thailand, and the staff of the Department of Pathobiological Sciences, School of Veterinary Medicine, University of Wisconsin, Madison, USA, for providing laboratory facilities and assistance in laboratory techniques.

\section{Funding}

Financial support from the Thailand Research Fund through the Royal Golden Jubilee PhD Programme (Grant No. PHD/0269/2549) is acknowledged.

\section{Availability of data and materials}

The sequence of interested target clone CE3 was submitted to the GenBank database under the accession number KX180136. The data used in the present study are available from the corresponding author upon request.

\section{Authors' contributions}

KP (PhD student) performed all experiments, provided data and results and contributed to manuscript preparation. CK supervised the animal experiments. TK supervised on molecular aspects of the study experiments. DW supervised the molecular part of the experiments involving clinical samples in Thailand. TPY supervised KP in the development of molecular part of the experiments at the University of Wisconsin and advised manuscript preparation. PD provided financial support from the Royal Golden Jubilee PhD Program through TRF and supervised all aspects of the thesis experiments in Thailand and advised manuscript preparation. All authors read and approved the final manuscript. 


\section{Ethics approval and consent to participate}

All animal protocols were approved by the Faculty of Tropical MedicineAnimal Care and Use Committee (FTM-ACUC) of Mahidol University (Project No. FTM-ACUC.2011/008). The human sera used in the present study were stored specimens that had been used in previous serological surveys/diagnostic testing. All patient identifiers had been removed, and no patient consent was required for this study. All procedures were approved by the Human Ethics Committee of the Faculty of Tropical Medicine, Mahidol University (Project No. TMEC 11-040).

\section{Competing interests}

The authors declare that they have no competing interests.

\section{Publisher's Note}

Springer Nature remains neutral with regard to jurisdictional claims in published maps and institutional affiliations.

\section{Author details}

'Department of Helminthology, Faculty of Tropical Medicine, Mahidol University, Bangkok 10400, Thailand. ${ }^{2}$ Mahidol-Bangkok School of Tropical Medicine, Faculty of Tropical Medicine, Mahidol University, Bangkok 10400, Thailand. ${ }^{3}$ Department of Microbiology and Immunology, Faculty of Tropical Medicine, Mahidol University, Bangkok 10400, Thailand. ${ }^{4}$ Department of Pathobiological Sciences, School of Veterinary Medicine, University of Wisconsin, Madison, Wisconsin 53706, USA.

Received: 6 November 2017 Accepted: 29 April 2018

Published online: 30 May 2018

\section{References}

1. World Health Organization. Control of foodborne trematode infections: report of a WHO study group. Geneva: World Health Organization; 1995.

2. Vijayan VK. Tropical parasitic lung diseases. Indian J Chest Dis Allied Sci. 2008;50:49-66.

3. Vajrasthira S, Paragonimiasis in Thailand. In: Harinasuta C, editor. Proceedings of the Fourth Southeast Asian Seminar on Parasitology and Tropical Medicine, Schistosomiasis and Other Snail-transmitted Helminthiases. Bangkok: Thai Watana Panich Press; 1969. p. 299-304.

4. Sugiyama H, Morishima Y, Rangsiruji A, Binchai S, Ketudat P, Kawanaka M. Application of multiplex PCR for species discrimination using individual metacercariae of Paragonimus occurring in Thailand. Southeast Asian J Trop Med Public Health. 2006;37(Suppl. 3):48-52.

5. Waikagul J. A new species of Paragonimus (Trematoda: Troglotrematidae) from a cat infected with metacercariae from mountain crabs Larnaudia larnaudii. J Parasitol. 2007:93:1496-500.

6. Indrawati I, Chaicumpa W, Setasuban P, Ruangkunaporn Y. Studies on immunodiagnosis of human paragonimiasis and specific antigen of Paragonimus heterotremus. Int J Parasitol. 1991;21:395-401.

7. Kong Y, Ito A, Yang HJ, Chung YB, Kasuya S, Kobayashi M, et al. Immunoglobulin $\mathrm{G}(\mathrm{IgG})$ subclass and IgE responses in human paragonimiases caused by three different species. Clin Diagn Lab Immunol. 1998;5:474-8.

8. Dekumyoy P, Setasuban P, Waikagul J, Yaemput S, Sa-nguankiat S. Human lung fluke (Paragonimus heterotremus): differentiation of antigenic proteins of adult worms by enzyme-linked immunoelectrotransfer blot technique. Southeast Asian J Trop Med Public Health. 1995;26:434-8.

9. Dekumyoy P, Waikagul J, Eom KS. Human lung fluke Paragonimus heterotremus: differential diagnosis between Paragonimus heterotremus and Paragonimus westermani infections by EITB. Trop Med Int Health. 1998;3:52-6.

10. Wongkham C, Maleewong W, Intapan P, Morakote N, Chaicumpa W. Partially purified antigens of Paragonimus heterotremus for serodiagnosis of human paragonimiasis. Southeast Asian J Trop Med Public Health. 1994;25:176-80.

11. Ito A, Xiao N, Liance M, Sato MO, Sako Y, Mamuti W, et al. Evaluation of an enzyme-linked immunosorbent assay (ELISA) with affinity-purified Em18 and ELISA with recombinant Em18 for differential diagnosis of alveolar echinococcosis: results of a blind test. J Clin Microbiol. 2002:40:4161-5.

12. Parikh R, Mathai A, Parikh S, Sekhar GC, Thomas R. Understanding and using sensitivity, specificity and predictive values. Indian J Ophthalmol. 2008;56:45-50.
13. Yoonuan $\mathrm{T}$, Nuamtanong $\mathrm{S}$, Dekumyoy $\mathrm{P}$, Phuphisut $\mathrm{O}$, Adisakwattana P. Molecular and immunological characterization of cathepsin L-like cysteine protease of Paragonimus pseudoheterotremus. Parasitol Res. 2016:115:4457-70.

14. Choo JD, Suh BS, Lee HS, Lee JS, Song CJ, Shin DW, Lee YH. Chronic cerebral paragonimiasis combined with aneurysmal subarachnoid hemorrhage. Am J Trop Med Hyg. 2003;69:466-9.

15. Chen Z, Zhu G, Lin J, Wu N, Feng H. Acute cerebral paragonimiasis presenting as hemorrhagic stroke in a child. Pediatr Neurol. 2008;39:133-6.

16. Ikeda T, Oikawa Y, Nishiyama T. Enzyme-linked immunosorbent assay using cysteine proteinase antigens for immunodiagnosis of human paragonimiasis. Am J Trop Med Hyg. 1996;55:434-7.

17. Ikeda T. Cystatin capture enzyme-linked immunosorbent assay for immunodiagnosis of human paragonimiasis and fascioliasis. Am J Trop Med Hyg. 1998:59:286-90.

18. Lee JS, Lee J, Kim SH, Yong TS. Molecular cloning and characterization of a major egg antigen in Paragonimus westermani and its use in ELISA for the immunodiagnosis of paragonimiasis. Parasitol Res. 2007;100:677-81.

19. Yu S, Zhang X, Chen W, Zheng H, Ai G, Ye N, Wang Y. Development of an immunodiagnosis method using recombinant PsCP for detection of Paragonimus skrjabini infection in human. Parasitol Res. 2017;116:377-85.

\section{Ready to submit your research? Choose BMC and benefit from:}

- fast, convenient online submission

- thorough peer review by experienced researchers in your field

- rapid publication on acceptance

- support for research data, including large and complex data types

- gold Open Access which fosters wider collaboration and increased citations

- maximum visibility for your research: over $100 \mathrm{M}$ website views per year

At BMC, research is always in progress.

Learn more biomedcentral.com/submissions 